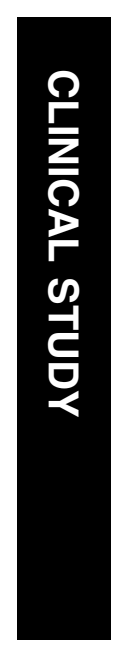

\title{
Refractive error and smoking habits in exudative age- related macular degeneration in a hospital-based setting
}

${ }^{1}$ Department of

Ophthalmology, Medical Faculty Mannheim of the Ruprecht-Karls-University, Heidelberg, Germany

${ }^{2}$ Department of Ophthalmology, People's Hospital, Peking University, Beijing, China

Correspondence: JB Jonas, Department of

Ophthalmology,

Universitäts-Augenklinik, Theodor-Kutzer-Ufer 1-3, 68167

Mannheim,

Germany

Tel: + 49621383 2242;

Fax: + 496213833803 .

E-mail: Jost.Jonas@

augen.ma.uni-heidelberg.de

Received: 5 February 2009 Accepted in revised form: 29 May 2009

Published online: 10 July 2009

Proprietary interest: None
Abstract

Purpose To assess and compare refractive error and smoking habits in patients with exudative age-related macular degeneration (AMD) in a clinical setting.

Methods The clinical comparative study included 379 patients (379 eyes) who underwent intravitreal application of an antivascular growth factor drug for the treatment of exudative AMD, and 191 patients without exudative macular degeneration and who underwent surgery for age-related cataract. Smoking status was compared with an agematched control group of the German population described in the census of 2003. The main outcome measures were refractive error, axial length, and data from a questionnaire on smoking habits.

Results The AMD group compared with the cataract group showed a significantly shorter axial length (23.31 \pm 0.75 vs $24.20 \pm 1.56 \mathrm{~mm}$; $P<0.001)$ and was significantly more hyperopic $(0.65 \pm 2.14$ vs $-1.71 \pm 4.57$ dioptres; $P<0.001$ ). After the exclusion of pseudophakic AMD patients and matching by age and gender, the difference of refractive error and axial length between both groups remained to be statistically significant $(P<0.001)$. The AMD group and the matched population group did not vary significantly in smoking history (age group: 55-75 years, current smokers: $18.4 \%$ vs $16.8 \%(P=0.64)$; former smokers: $23.2 \%$ vs $24.9 \%(P=0.66)$; age group $>75$ years, current smokers: $6.3 \%$ vs $6.4 \%$ $(P=0.97)$; former smokers: $19.7 \%$ vs $22.8 \%$ $(P=0.25))$.

Conclusions In our setting, an association was found between short axial length and
AMD. We were not able to confirm the previously reported link between smoking and AMD.

Eye (2010) 24, 648-652; doi:10.1038/eye.2009.160; published online 10 July 2009

Keywords: exudative age-related macular degeneration; hyperopia; smoking; macular degeneration; visual impairment

Population-based studies, such as the Rotterdam Study, the Beaver Dam Study, and the Blue Mountains Eye Study have shown that smoking is a major risk factor for age-related macular degeneration (AMD) ${ }^{1-12}$ In contrast, the findings of an association between hyperopia and AMD have been inconclusive so far. Although the Rotterdam Study, the AgeRelated Eye Disease Study, the Blue Mountains Eye Study, the French DMLA Study, and the Beijing Eye Study found an association between hyperopia and AMD, other large-scaled population-based investigations did not detect a correlation between both parameters. ${ }^{13-19}$

In view of the discrepancy between the studies, it was the purpose of our study to re-assess the relationship between $\mathrm{AMD}$, refractive error, and smoking habits of patients attending a referral hospital for the treatment of exudative AMD.

\section{Methods}

The clinical comparative hospital-based study included 379 patients who were treated for exudative AMD by an intravitreal injection of an anti-vascular endothelial growth factor drug from December 2005 to July 2008. In general, an intravitreal injection of an anti-Vascular 
Endothelial Growth Factor has been recommended to all patients with an exudative AMD in our hospital, unless the lesion is extensive with marked subretinal fibrosis. For all patients, the diagnosis was substantiated by ophthalmoscopy and optical coherence tomography. In case of doubt, fluorescein angiography confirmed the diagnosis. Inclusion criteria were: (1) the eyes were phakic or in the case of pseudophakic eyes, there were records of the refractive error before cataract surgery; and (2) an age of more than 50 years. For the statistical analysis, the refractive error data only before cataract surgery were taken into account. Eyes after corneal refractive surgery were excluded.

A control group consisted of 191 patients undergoing surgery for age-related cataract without ophthalmoscopic signs of exudative AMD, such as a detachment of the retinal pigment epithelium, subfoveal hemorrhages or fibrosis, or intraretinal or subretinal oedema. Inclusion criterion for the cataract group was an age equal to or higher than 50 years.

All patients underwent an ophthalmologic examination including refractometry for the assessment of the best-corrected visual acuity, tonometry, and slit lamp assisted biomicroscopy of the anterior segment and posterior segment of the eye. The refractive data were converted into the spherical equivalent. In addition, a biometry was carried out to measure the axial length. If the eyes were pseudophakic, data on the refractive error obtained before the cataract surgery were used. The smoking habits were assessed by a questionnaire in the patients with AMD. According to the results, the patients were divided into former smokers, current smokers, and non-smokers.

The prevalence for smoking in the exudative AMD patients was compared with the corresponding agematched subgroup of the German population, as described in the census of $2003 .^{20}$

The statistical analysis was carried out using a commercially available software package (SPSS for Windows, version 16.0, SPSS, Chicago, IL, USA.). Where appropriate, independent $t$-test, $\chi^{2}$-test, and multivariate logistic regression were used. Confidence intervals were presented. All $P$-values were two-sided and were considered statistically significant when the values were less than 0.05 . Only one eye per patient was included in the study.

\section{Results}

The study group with exudative AMD included 379 patients ( 241 women) with a mean age of $77.1 \pm 7.6$ years (mean \pm SD; median: 78 years; range: $55-94$ years). Mean intraocular pressure measured $14.7 \pm 2.9 \mathrm{~mm} \mathrm{Hg}$ (range: 6-26 mm Hg). There were $220(58.0 \%)$ phakic patients and $159(42.0 \%)$ pseudophakic patients. The control group consisted of 191 patients (96 women) undergoing cataract surgery with a mean age of $73.3 \pm 10.4$ years (median: 75 years; range: 50-97 years). The mean intraocular pressure was $15.3 \pm 3.0 \mathrm{~mm} \mathrm{Hg}$ (range: 8-25 mm Hg).

The mean spherical equivalent in the exudative AMD group was $0.65 \pm 2.14$ dioptres (range: $-15.5-+6.5$ dioptres), and in the cataract group, it was $-1.71 \pm 4.57$ dioptres (range: $-19.1-+6.0$ dioptres). The patients of the AMD group were significantly more hyperopic than the patients of the cataract group $(P<0.001)$. Correspondingly, the proportion of hyperopic patients was significantly higher in the AMD group than the cataract group $(65.2 \%$ vs $36.7 \%, P<0.001)$. In a similar manner, the axial length was significantly shorter in the patients with exudative AMD than in the patients undergoing cataract surgery $(23.31 \pm 0.75 \mathrm{~mm}$ (range: 21.30-28.09 mm) vs $24.20 \pm 1.56 \mathrm{~mm}$ (range: $21.74-$ $32.88 \mathrm{~mm}) ;(P<0.001)$.

To exclude a potentially confounding effect of age, gender, and previous cataract surgery in the AMD group, all pseudophakic eyes were excluded. In a second step, the patients of the AMD group and of the control group were matched for age and gender. It showed that again the AMD study, as compared with the control group, was significantly more hyperopic $(1.19 \pm 2.15$ dioptres vs $-1.53 \pm 4.29$ dioptres; $P<0.001$ ) (Figure 1) and had a higher proportion of hyperopic patients $(68.0 \%$ vs $26.5 \%$, $P<0.001)$, and a shorter axial length $(23.19 \pm 0.77 \mathrm{~mm} v \mathrm{~s}$ $24.15 \pm 1.39 \mathrm{~mm} ; P<0.001$ ) (Figure 2).

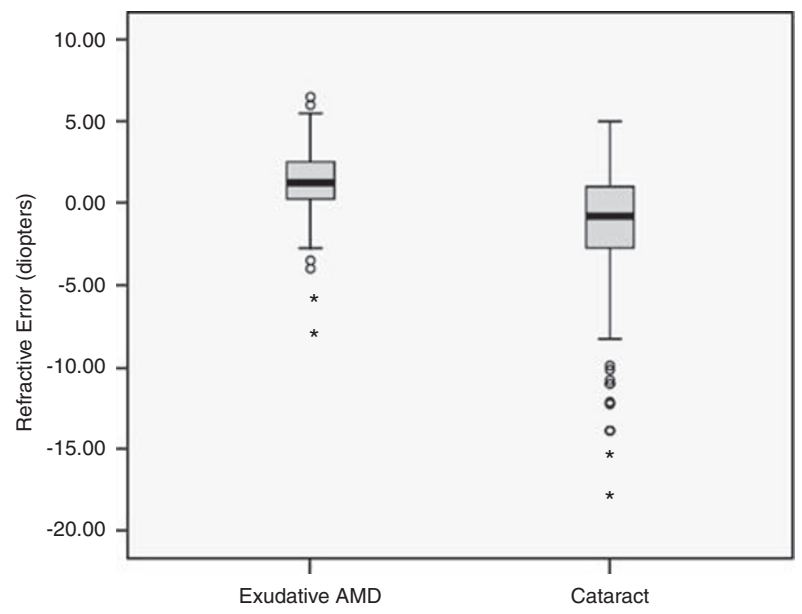

Figure 1 Boxplots showing the distribution of refractive error in age-, gender-, and phakic status- matched patients with exudative age-related macular degeneration ('Exudative AMDGroup') and patients undergoing surgery for age-related cataract ('Cataract Group'). The difference between both groups was statistically significant $(P<0.001 ; 95 \%$ confidence interval of the difference: $1.89,3.57)$. 


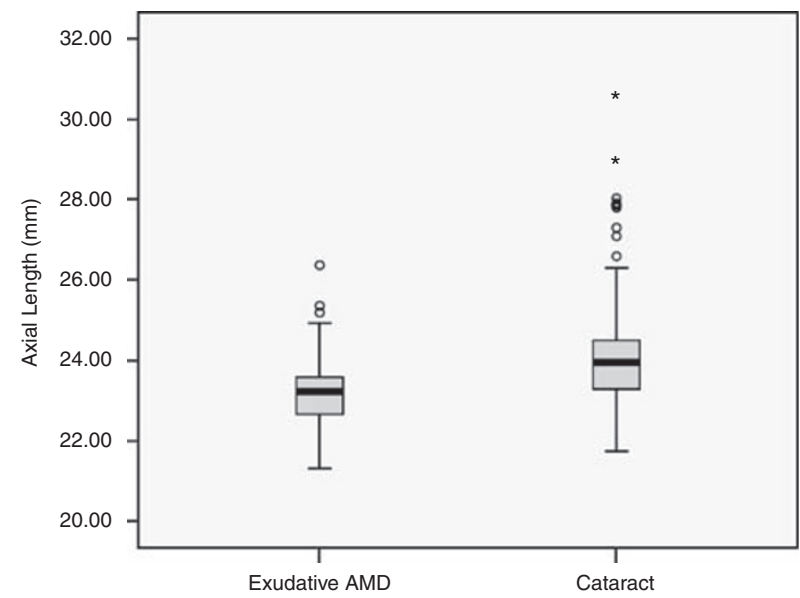

Figure 2 Boxplots showing the distribution of axial length in age-, gender-, and phakic status- matched patients with exudative age-related macular degeneration ('Exudative AMDGroup') and patients undergoing surgery for age-related cataract ('Cataract Group'). The difference between both groups was significant $(P<0.001 ; 95 \%$ confidence interval of the difference: -1.24 and -0.69 ).

Table 1 Characteristics of a study group consisting of patients undergoing intravitreal bevacizumab therapy of exudative agerelated macular degeneration (AMD) and of a control group consisting of patients undergoing surgery for age-related cataract

\begin{tabular}{|c|c|c|c|}
\hline Number & $\begin{array}{c}\text { Exudative AMD } \\
379\end{array}$ & $\begin{array}{c}\text { Cataract } \\
191\end{array}$ & P-value \\
\hline \multicolumn{4}{|l|}{ Age (years) } \\
\hline Mean & $77.1 \pm 7.6$ & $73.3 \pm 10.4$ & $<0.001$ \\
\hline Median & 78 & 75 & \\
\hline Range & $55-94$ & $50-97$ & \\
\hline Female & 241 & 96 & 0.002 \\
\hline Diabetes & $55(14.55 \%)$ & $23(12.0 \%)$ & 0.60 (n.s.) \\
\hline \multicolumn{4}{|c|}{ Intraocular pressure $(\mathrm{mm} \mathrm{Hg})$} \\
\hline Mean & $14.7 \pm 2.9 \mathrm{~mm} \mathrm{Hg}$ & $15.3 \pm 3.0 \mathrm{~mm} \mathrm{Hg}$ & 0.02 \\
\hline Median & 14 & 15 & \\
\hline Range & $6-26$ & $8-25$ & \\
\hline Phakic & $220(58.0 \%)$ & $191(100.0 \%)$ & $<0.001$ \\
\hline
\end{tabular}

$P$-value: statistical significance of the difference between both groups. n.s.: statistically not significant.

Finally, a binary logistic regression analysis was carried out, in which all patients of both groups were included. The diagnosis (AMD vs control group) was used as a dependent binary factor, and refractive error, age, lens status, and gender served as independent parameters. It showed that AMD was significantly associated with hyperopic refractive error $(P<0.001)$ and age $(P<0.001)$.
Compared with the national survey of smoking in the German population, both in the age group of 55-75 years and in the age group of $75+$ years, the percentage of current smokers, former smokers, and non-smokers did not vary significantly between the AMD group and the comparative group in the national survey (Table 2). If the whole group was taken, the AMD study group as compared with the census control group had a significantly $(P=0.03)$ lower percentage of current smokers, and correspondingly, a significantly $(<0.01)$ higher percentage of non-smokers (Table 2).

\section{Discussion}

Our study showed that patients, who were treated for exudative AMD in a referral centre and who were compared with patients treated for age-related cataract, had a significantly shorter axial length $(P<0.001)$ and were significantly more hyperopic $(P<0.001)$. In addition, the AMD group and an age-matched population control group did not vary significantly in smoking status.

With respect to the association between hyperopia and AMD, the results of our study are in agreement with the Rotterdam Study, the French DMLA Study, the AgeRelated Eye Disease Study Research, and the Beijing Eye Study, in which an association between AMD and hyperopia was described. ${ }^{13,14,16,17}$ The present hospitalbased study supports a previous hospital-based investigation by Böker et $a l^{21}$ who found an increasing risk for the development of exudative AMD with increasing amount of hyperopia. In a parallel manner, Sandberg et $a l^{22}$ examined and compared the refractive error of 198 patients with unilateral exudative AMD with the refractive error of 129 patients with bilateral nonexudative AMD. By comparing the better eyes of the two groups, patients with the unilateral exudative form had an average spherical equivalent that was 1.0 dioptre more hyperopic than that of patients with the bilateral non-exudative form $(P<0.001)$. Patients with a refractive error of +0.75 dioptre or greater were more likely to have the exudative form compared with patients with other refractive errors (odds ratio: $2.40 ; P<0.001$ ). The authors concluded that hyperopia was a risk factor for choroidal neovascularization among patients referred with age-related macular degeneration. Reports by Maltzman et $a l^{23}$ and by Hyman et $a l^{24}$ also support an association between hyperopia and AMD. The results of our study are partially in agreement with the Blue Mountains Eye Study, in which a statistically weak association between AMD and hyperopia was described in a first report in $1998 .{ }^{15}$ In a second report on the incidence of AMD in the Blue Mountains Eye Study, however, a statistically significant association between 
Table 2 Prevalence (95\% confidence intervals) of smoking in patients with exudative age-related macular degeneration (AMD), compared with the prevalence of smoking in the German population matched by age

\begin{tabular}{|c|c|c|c|c|c|c|}
\hline & \multicolumn{2}{|c|}{ Current smoker } & \multicolumn{2}{|c|}{ Former smoker } & \multicolumn{2}{|r|}{ Non-smoker } \\
\hline & No. & Propotion & No. & Propotion & No. & Propotion \\
\hline \multicolumn{7}{|l|}{ Age 55-75 years } \\
\hline AMD Study Group & 23 & $18.4 \%(11.6-25.2 \%)$ & 29 & $23.2 \%(15.8-30.6 \%)$ & 73 & $58.4 \%(49.8-67.0 \%)$ \\
\hline Matched German population & 2902 & $16.8 \%$ & 4301 & $24.9 \%$ & 10055 & $58.3 \%$ \\
\hline$P$-value & & 0.64 (n.s.) & & 0.66 (n.s.) & & 0.98 (n.s.) \\
\hline \multicolumn{7}{|l|}{ Age $\geqslant 75$ years } \\
\hline AMD Study Group & 16 & $6.3 \%(3.3-9.3 \%)$ & 50 & $19.7 \%(14.8-24.6 \%)$ & 188 & $74.0 \%(68.6-79.4 \%)$ \\
\hline Matched German population & 349 & $6.4 \%$ & 1250 & $22.8 \%$ & 3884 & $70.8 \%$ \\
\hline$P$-value & & 0.97 (n.s.) & & 0.25 (n.s.) & & 0.28 (n.s.) \\
\hline \multicolumn{7}{|l|}{ Total } \\
\hline AMD Study Group & 39 & $10.3 \%(7.2-13.4 \%)$ & 79 & $20.8 \%(16.8-24.9 \%)$ & 261 & $68.9 \%(64.2-73.5 \%)$ \\
\hline Matched German population & 3251 & $14.3 \%$ & 5551 & $24.4 \%$ & 13939 & $61.3 \%$ \\
\hline$P$-value & & 0.03 & & 0.11 (n.s.) & & $<0.01$ \\
\hline
\end{tabular}

$P$-value: statistical significance of the difference between the study group and the age-matched control group.

n.s.: statistically not significant.

AMD and hyperopia was no longer detected. ${ }^{18}$ The results of the present study are in disagreement with the findings of other population-based studies, which were carried out in several countries on various ethnic groups. ${ }^{18}$

With respect to smoking, our hospital-based study did not detect a statistically significant association between smoking and AMD. Quite in contrast, if the whole study group was considered, the AMD study group as compared with the census control group had a significantly $(P=0.03)$ lower percentage of current smokers, and correspondingly, a significantly $(<0.01)$ higher percentage of non-smokers (Table 1). It is in contrast to most population-based studies, which have described an association between smoking and AMD. ${ }^{1-12}$ To cite a recent example, in the Beaver Dam Study, smoking was related to the long-term incidence and progression of AMD after controlling for age, sex, and baseline severity of $\mathrm{AMD}^{3}$. It is in contrast to the present hospital-based study, in which the AMD group and a control group from a general population census did not vary significantly in the frequency of current smokers, former smokers, or non-smokers. In a parallel manner, the prospective Copenhagen City Eye Study did not find an association between smoking and AMD nor did the Beijing Eye Study. ${ }^{17,25}$ The question arises why the studies differed in the finding of associations between smoking and AMD, or hyperopia and AMD. One may discuss whether the described associations between smoking and AMD were because of a confounding effect. Smoking is associated with a low socioeconomic background (Beijing Eye Study, unpublished data). A low level of education is associated with hyperopic refractive error (Beijing Eye Study, unpublished data). Correspondingly, smokers vs non-smokers were significantly more hyperopic in the Beijing Eye Study (unpublished data). Hyperopia has, however, been described to be associated with AMD in some studies. ${ }^{13,14,16,17,21-24}$ In some of the population-based studies, in which an association between AMD and smoking was described, the socioeconomic background and hyperopia as potentially confounding factors were not included in the statistical multivariate analysis.

There are limitations of our study. First, the most important limitation is its study design as a hospitalbased investigation. It is difficult to know the effect of selection bias in this study. Owing to this inevitable referral bias, any population-based study is superior to a hospital-based investigation, if the number of study participants affected with the disease is comparable. In our study, however, the number of patients with exudative AMD exceeded, by far, the number of subjects with exudative AMD examined in population-based studies. In addition, one may consider that the control group for the comparison of the smoking behavior was taken from a large census, which may be comparable with a large population-based study population. Second, the hospital based control group consisted of patients undergoing routine cataract surgery. Nuclear cataract, however, is associated with a myopic shift, so that these patients were a priori likely to be more myopic than the patients of the AMD study group. If, however, axial length instead of refractive error was considered, the patients with exudative AMD had a significantly $(P<0.001)$ shorter axial length than the patients undergoing cataract surgery (Figure 2), suggesting that independently of the cataract related myopic shift, the patients of the AMD group were more hyperopic than the patients of the control group. 
In conclusion, in the clinical setting of our study, the association between shorter axial length and exudative AMD was statistically significant, whereas no significant association was noted between smoking and exudative AMD. It may lead to studies examining whether additional, confounding factors may influence the associations between the prevalence of exudative AMD and other parameters.

\section{References}

1 Vingerling JR, Hofman A, Grobbee DE, de Jong PT. Agerelated macular degeneration and smoking. The Rotterdam Study. Arch Ophthalmol 1996; 114: 1193-1196.

2 Smith W, Mitchell P, Leeder SR. Smoking and age-related maculopathy; The Blue Mountain Eye Study. Arch Ophthalmol 1996; 114: 1518-1523.

3 Klein R, Klein BE, Moss SE. Relation of smoking to the incidence of age-related maculopathy. The Beaver Dam Eye Study. Am J Epidemiol 1998; 15: 147:103-110.

4 Seddon JM, George S, Rosner B. Cigarette smoking, fish consumption, omega-3 fatty acid intake, and associations with age-related macular degeneration: The US Twin Study of Age-Related Macular Degeneration. Arch Ophthalmol 2006; 124: 995-1001.

5 Arnarsson A, Sverrisson T, Stefánsson E, Sigurdsson H, Sasaki H, Sasaki K et al. Risk factors for five-year incident age-related macular degeneration: The Reykjavik Eye Study. Am J Ophthalmol 2006; 142: 419-428.

6 Tan JS, Mitchell P, Kifley A, Flood V, Smith W, Wang JJ. Smoking and the long-term incidence of age-related macular degeneration: The Blue Mountains Eye Study. Arch Ophthalmol 2007; 125: 1089-1095.

7 Chakravarthy U, Augood C, Bentham GC, de Jong PT, Rahu M, Seland J et al. Cigarette smoking and age-related macular degeneration in the EUREYE Study. Ophthalmology 2007; 114: 1157-1163.

8 Neuner B, Wellmann J, Dasch B, Behrens T, Claes B, Dietzel $\mathrm{M}$ et al. Modeling smoking history: a comparison of different approaches in the MARS study on age-related maculopathy. Ann Epidemiol 2007; 17: 615-621.

9 Chang MA, Bressler SB, Munoz B, West SK. Racial differences and other risk factors for incidence and progression of age-related macular degeneration: Salisbury Eye Evaluation (SEE) Project. Invest Ophthalmol Vis Sci 2008; 49: 2395-2402.

10 Cong R, Zhou B, Sun Q, Gu H, Tang N, Wang B. Smoking and the risk of age-related macular degeneration: a meta-analysis. Ann Epidemiol 2008; 18: 647-656.

11 Kawasaki R, Wang JJ, Ji GJ, Taylor B, Oizumi T, Daimon M et al. Prevalence and risk factors for age-related macular degeneration in an adult Japanese population: The Funagata Study. Ophthalmology 2008; 115: 1376-1381.

12 Klein R, Knudtson MD, Cruickshanks KJ, Klein BE. Further observations on the association between smoking and the long-term incidence and progression of age-related macular degeneration: The Beaver Dam Eye Study. Arch Ophthalmol 2008; 126: 115-121.

13 Ikram MK, van Leeuwen R, Vingerling JR, Hofman A, de Jong PT. Relationship between refraction and prevalent as well as incident age-related maculopathy: The Rotterdam Study. Invest Ophthalmol Vis Sci 2003; 44: 3778-3782.

14 Age-Related Eye Disease Study Research Group. Risk factors associated with age-related macular degeneration. A case-control study in the age-related eye disease study: AgeRelated Eye Disease Study Report Number 3. Ophthalmology 2000; 107: 2224-2232.

15 Wang JJ, Mitchell P, Smith W. Refractive error and agerelated maculopathy: The Blue Mountains Eye Study. Invest Ophthalmol Vis Sci 1998; 39: 2167-2171.

16 Chaine G, Hullo A, Sahel J, Soubrane G, Espinasse-Berrod MA, Schutz D et al. Case-control study of the risk factors for age related macular degeneration. France-DMLA Study Group. Br J Ophthalmol 1998; 82: 996-1002.

$17 \mathrm{Xu} \mathrm{L}, \mathrm{Li}$ Y, Zheng Y, Jonas JB. Associated factors for age related maculopathy in the adult population in China: The Beijing Eye Study. Br J Ophthalmol 2006; 90: 1087-1090.

18 Wong TY, Klein R, Klein BE, Tomany SC. Refractive errors and 10-year incidence of age-related maculopathy. Invest Ophthalmol Vis Sci 2002; 43: 2869-2873.

19 Wang JJ, Jakobsen KB, Smith W, Mitchell P. Refractive status and the 5-year incidence of age-related maculopathy: The Blue Mountains Eye Study. Clin Experiment Ophthalmol 2004; 32: $255-258$.

20 Leben und Arbeiten in Deutschland. Mikrozensus 2003. Tabellenanhang zur Pressebroschüre. Statistisches Bundesamt: Wiesbaden, Germany, 2004 Tabelle 73.

21 Böker T, Fang T, Steinmetz R. Refractive error and choroidal perfusion characteristics in patients with choroidal neovascularization and age-related macular degeneration. Ger J Ophthalmol 1993; 2: 10-13.

22 Sandberg MA, Tolentino MJ, Miller S, Berson EL, Gaudio AR. Hyperopia and neovascularization in agerelated macular degeneration. Ophthalmology 1993; 100 1009-1013.

23 Maltzman BA, Mulvihill MN, Greenbaum A. Senile macular degeneration and risk factors: a case-control study. Ann Ophthalmol 1979; 11: 1197-1201.

24 Hyman LG, Lilienfeld AM, Ferris III FL, Fine SL. Senile macular degeneration: a case-control study. Am J Epidemiol 1983; 118: 213-227.

25 Buch H, Vinding T, la Cour M, Jensen GB, Prause JU, Nielsen NV. Risk factors for age-related maculopathy in a 14-year follow-up study: The Copenhagen City Eye Study. Acta Ophthalmol 2005; 83: 409-418. 